\title{
Exploring learners' emotions and emotional profiles in simulation-based medical education
}

\author{
Tuulikki Keskitalo \\ Lapland University of Applied Sciences
}

\author{
Heli Ruokamo \\ University of Lapland
}

\begin{abstract}
Medical education can be emotionally charged for many reasons, while simulation-based activities in particular are designed to generate emotional reactions. However, few studies have concentrated on the relationship between learning and emotions in this field, despite widespread interest in the topic in other areas. The aim of this research was to study the emotional experiences of participants before and after simulation-based teaching and learning activities. Data were collected from 238 participants using pre- and postquestionnaires and analysed using descriptive statistics, a paired samples $t$ test, factor analysis, Cronbach's alpha, a linear regression analysis and k-means cluster analysis. Participants were clustered into engaged, neutral and anxious learners based on their emotional profiles. The results showed that simulation-based learning invoked mainly positive emotions, whereas negative emotions decreased to a slight degree during an educational course. This study also revealed variables that may explain emotional variations. The article provides practical implications of the findings for simulation-based medical education and higher education in general.
\end{abstract}

Implications for practice or policy:

- Positive emotions in simulation-based education can be promoted by challenging participants and providing activities at the appropriate level of difficulty.

- Learners may benefit from individual guidance and support, reducing their anxiety and building their sense of medical competence.

- Being cognisant of emotional subgroups among participants can help tailor instruction for individual learners.

- Simulation-based education can be targeted to educate learners to cope with difficult emotions and how to seek help.

Keywords: simulation-based learning environment (SBLE), medical education, learners, emotions, quantitative

\section{Introduction}

Understanding emotions and their relationship to learning and behaviour may be key to the development of educational settings and work environments that are more beneficial for learners' well-being and learning outcomes (e.g., Immordino-Yang, 2011; Lonka \& Ketonen, 2012; Postareff et al., 2017). However, research questions on the relationship between emotions and learning in higher education have only recently begun to be asked, due to increased understanding of the relationship between these topics (Duffy et al., 2016; Lonka \& Ketonen, 2012; White, 2013). This is significant, as education, and especially medical education, can be emotionally overwhelming for many reasons (e.g., Hope \& Henderson, 2014; Leslie \& Hutchinson, 2018; McConnell \& Eva, 2012; Taylor, 2010). Simulation-based learning environments (SBLEs) have increasingly been used in medical education (Helle \& Säljö, 2012), and the simulation scenarios are intended to generate emotional experiences in learners (Bryson \& Levine, 2008; DeMaria et al., 2010). A few studies have concentrated on learning and emotions in simulation-based medical education (Andreatta et al., 2010; Bryson \& Levine, 2008; Duffy et al., 2015; Duffy et al., 2016; McConnell \& Eva, 2012), but they have focused primarily on the relationship between stress and performance (Andreatta et al., 2010; Fraser et al., 2012; Schlairet et al., 2015), although many other emotions are also related to learning (Duffy et al., 2015; Duffy et al., 2016; Lonka \& Ketonen, 2012; Pekrun et al., 2002; Peterson et al., 2015; Postareff et al., 2017). 
The purpose of this study was to investigate learners' emotions before and after simulation-based medical education and determine what emotional profiles could be found among participants (e.g., Lonka \& Ketonen, 2012), so that clinical teachers and learners can better understand learners' emotions and the consequences of those emotions for learning and behaviour. Generally, simulation-based medical education refers to teaching and learning activities conducted in a realistic healthcare environment. It has similarities with many modern pedagogical models, such as case-based or problem-based learning, in which the learners' activity is central to learning. Usually, the learning process in simulation is scripted with the following phases: introduction, simulation and scenario briefing, scenarios and debriefing (e.g., Keskitalo, 2015). In this study, we refer to SBLEs to emphasise that these environments are intended for learning purposes (Keskitalo, 2015). In addition, we refer to learners or participants rather than students because the learners in the SBLE may indeed be medical or healthcare students, but they may also be professionals already working in the field.

Next, we discuss previous studies on learning and emotions, with a special focus on simulation-based medical education. Thereafter, we introduce the study's research questions and methods. Finally, we present and discuss of the study's results.

\section{Literature review}

Emotions refer to the affective contents, states and experiences of our lived experiences (Fredrickson, 2001; McConnell \& Eva, 2012; Schnall, 2010) and thus play a crucial role in learning in higher education (Damasio, 2001; Immordino-Yang \& Faeth, 2010; Pekrun et al., 2002; Postareff et al., 2017; Schutz \& DeCuir, 2002; Schutz et al., 2010). However, emotions are multifaceted, involving not only different psychological states, such as subjective feelings and cognitive evaluations, but also expressive and physiological changes in our faces and bodies (Duffy et al., 2016; Fredrickson, 2001; Immordino-Yang, 2011; Mauss \& Robinson, 2009). For example, each emotion plays out differently in the face and body, which are regulated through the brain system. The brain system is also involved in making cognitive evaluations of our emotions (Immordino-Yang, 2011). These conscious feelings help individuals adjust their behaviour to challenges confronted in the environment (Damasio, 1996; Immordino-Yang, 2011), such as those posed by the learning environment (e.g., Lazarus, 1991). Another characteristic of emotions is that they are constructed in certain sociocultural contexts (e.g., Crossman, 2007; Immordino-Yang, 2011; Immordino-Yang \& Damasio, 2007; Schutz et al., 2010); for example, we learn to show our emotions according to the values of the surrounding society.

Studies have categorised emotions into three interrelated constructs: affective tendencies, core affects and emotional experiences (Schutz et al., 2010). According to Schutz et al. (2010), affective tendency refers to an individual's predisposition towards certain ways of being in the world; thus, affective tendency is more long-lasting than core affect. Affective tendencies can also be characterised as objectless (Fredrickson, 2001). Core affects refer to the feelings experienced at a given point in time (Schutz et al., 2010). Core affects are further classified into two dimensions: valence and arousal (McConnell \& Eva, 2012; Pons et al., 2010; Schnall, 2010; Schutz et al., 2010). According to Schnall (2010), valence refers to whether the experience is viewed positively or negatively, and arousal refers to whether an individual experiences the emotion as activating or deactivating (see also Reisenzein, 1994). However, emotions can also be categorised as neutral (Nummenmaa et al., 2013). In this study, we were specifically interested in the valence aspect of emotional experience.

Generally, positive emotions are more conducive for learning than negative ones (Duffy et al., 2016; McConnell \& Eva, 2012; Postareff et al., 2017), as they, according to Fredrickson (2001), "facilitate approach behaviour" (p. 219). For example, learners who experience positive affect are more likely to take part in and engage with their learning environment. Positive emotions are also linked to deep approaches to learning (Trigwell et al., 2012). However, the relationship between emotions and learning is far more complex than this (Fraser et al., 2012; Peterson et al., 2015; Schutz et al., 2010). Dreisbach and Goschke (2004) concluded that positive emotions increase cognitive flexibility, verbal fluency and decision-making, but they also reduce perseverance and increase distractibility (see also Duffy et al., 2016). In addition, positive emotions facilitate creative thinking, whereas negative emotions tend to narrow people's thinking to a focus on details (Fredrickson, 2001; McConnell \& Eva, 2012). This may be why negative emotions facilitate more accurate decision-making (Staal, 2004). Stress and anxiety have quite negative connotations, but both may, in some cases, be beneficial for learning (DeMaria et al., 2010; Pekrun et al., 2006; Postareff 
et al., 2017). However, both positive and negative emotions can be harmful for learning when they focus the learner's attention on something that is irrelevant to the learning task (Duffy et al., 2016). According to Lonka and Ketonen (2012), positive activating emotions (e.g., interest) are more conducive for learning than positive deactivating emotions (e.g., relaxation). As Lonka and Ketonen (2012) have pointed out, "It appeared that being either slightly anxious or engaged was better than remaining unstressed or even careless" (p. 72). Therefore, it seems that both positive and negative emotions are, to some degree, beneficial for learning, but further research is needed to clarify this (see also Duffy et al., 2015; Postareff et al., 2017).

The context of this study is SBLE, concentrating specifically on emotions that learners experience before and after simulation sessions. In an SBLE, scenarios and materials are usually constructed to elicit particular emotions in learners (DeMaria et al., 2010). Emotional stressors are added to instruction to enhance learners' memorisation of course content (Bryson \& Levine, 2008; Immordino-Yang \& Faeth, 2010) and for learners to practise performing under stress. For example, in extreme cases, the learning goal may be the delivery of bad news (Jacques et al., 2011). These simulations are beneficial because real-life situations in a healthcare environment may be challenging and stressful or cause cognitive overloading (e.g., Andreatta et al., 2010). For these reasons, it is important to create an emotionally safe SBLE early on and to ensure that the learners feel comfortable sharing their thoughts and feelings. Simulation training requires learners' willingness to engage in and reflect on their emotions and to consider how emotions influence motivation, performance and so on (Dieckmann \& Rall, 2008; Keskitalo, 2015). The emotional experiences that occur during simulation-based learning are usually reflected upon in debriefing sessions after the simulation experience. This discussion is usually considered the most important phase of simulation-based healthcare education (e.g., Keskitalo, 2015).

Emotions occurring during simulation-based education can also be viewed as academic emotions. Academic emotions were first described by Pekrun et al. (2002; see also Lonka \& Ketonen, 2012), who described them simply as emotions that occur in academic settings. According to Pekrun et al. (2002), academic emotions, including emotions surrounding learners' self-regulation, achievement and personality antecedents and the instructional and social environment, relate significantly to learning. Academic emotions can be further classified into achievement emotions, defined as emotions linked to academic achievements such as tests, assignments and performance (Pekrun, 2006).

Participants' emotional reactions to simulation-based learning have been shown to enhance learning and the recall of experiences and information (e.g., DeMaria et al., 2010). However, studies have focused mainly on learners' reactions to stress in terms of simulation-based learning (Andreatta et al., 2010; Alinier et al., 2004; Alinier et al., 2006) and the relationship between cognitive load, emotions and performance (Fraser et al., 2012; Schlairet et al., 2015). Studies have agreed that simulation-based education evokes mainly positive emotions (e.g., Schlairet et al., 2015). However, there may be learner groups that experience simulation-based education in a more stressful way than other groups. For example, for learners with limited clinical experience (Fraser et al., 2012) or for low-performing participants (Schlairet et al., 2015) simulation-based education can be a cognitively and emotionally overwhelming experience. Duffy et al. (2015) also found that negative emotions (e.g., anxiety) are preceded often by lower-order cognitive and metacognitive processes, which thus may affect team performance during simulated emergency training. Such information on learners' varying emotional profiles could be particularly helpful when planning simulation-based education and adjusting the emotional stressors for a particular learner group (DeMaria et al., 2010; Pekrun et al., 2002) and also in promoting positive emotions and overall well-being (see Postareff et al., 2017). Studies examining learners' emotional profiles in simulation-based medical education are lacking, although they have been studied quite extensively elsewhere (cf. Lonka \& Ketonen, 2012; Postareff et al., 2017). Therefore, further research on this topic is warranted.

\section{Research questions}

With this background, we set the following research questions for this study:

(1) Which variables explain learners' positive and negative emotions before and after simulationbased education?

(2) What emotional profiles can be found among learners? 


\section{Methods}

\section{Participants}

Data were collected from 238 participants (122 males and 116 females). The learners were mostly medical students $(n=100)$ and junior physicians $(n=119)$ specialising mainly in anaesthesia or emergency medicine. Other participants were healthcare practitioners $(n=17)$, such as nurses or occupational therapists. Two participants did not report their field of study. The median age of the respondents was 29 (range 22-39 years old). Most of the participants had previously participated in simulation-based activities.

Before the study, research permission was applied for and approved by the institutional review board. Thereafter, consent was obtained from the participants, and the purpose and aims of the study were explained. The participants were also informed that they would not receive any compensation for taking part in this study. It was also emphasised that participation was voluntary and that they could withdraw from the study at any time. However, all the participants decided to take part.

\section{Research context}

Data were collected from three different SBLEs between 2010 and 2016. The courses were selected based on accessibility and availability. The simulation centres had many simulation rooms available. An operating room, intensive care unit, emergency department or ward was usually set up for the simulation exercise. The learning environment also included various computer-directed patient simulators (adult, child and infant). During courses, all activities were prepared by the facilitators and carried out collaboratively in a group format. Two to four participants were usually assigned to one group. Participants who did not take part in a scenario watched it from a separate room via a television.

The basic course structure included an introduction to the course's topic, goals and ground rules, familiarisation with the environment, the scenario (i.e., patient case) and the debriefing (Keskitalo, 2015). Some courses also included a short theory input between the introduction and familiarisation phases, which is a typical structure for many simulation-based healthcare courses (Dieckmann, 2009). Each course lasted from 1 to 9 hours, depending on the learning objectives or the number of the learners. In a 9-hour course, there were usually five patient scenarios with debriefings, which the learners progressed through during the day. The course topics and patient cases were usually related to emergency medicine, anaesthesia crisis resource management or paediatric and adult anaesthesia. For example, a typical case in an anaesthesia crisis resource management course was chronic obstructive pulmonary disease exacerbation.

During the simulation sessions, the facilitators were most active during the introduction and familiarisation phases. Learners, however, led the scenarios, in which they actively tried to solve simulated patient cases collaboratively without the facilitators' intervention. Usually, there were also specific roles assigned for learners: one would take the central role in leading the specific case by, for example, pretending to be an attending anaesthesiologist in the specific case. The learners' roles often varied during the day so that everyone could take the role of leader as well as observer. Thereafter, the debriefing was held, typically lasting longer than the scenarios. Debriefing is ideally directed by the learners' needs (i.e., discussion of emotions) and initiatives, but often it also requires the instructor's guidance (e.g., Rudolph et al., 2008).

\section{Data collection and analysis}

The pre- and post-questionnaires used in this study were originally developed for measuring the participants' expectations for and experiences of meaningful learning in SBLEs (see Keskitalo, 2012). They consisted of Likert-type questions related to the learners' evaluation of expectations for and experiences of the meaningful learning processes in an SBLE, such as "my problem-solving skills will develop/have developed during the course". Each of the 39 statements was scored on a continuum $(1=$ does not describe my expectations at all, $5=$ describes my expectations very well). The questionnaires also included 29 Likerttype questions $(0=$ not at all, $5=$ to a great extent $)$ focused on the emotions that learners experienced at a given time point (i.e., right before and right after the course) (Hakkarainen et al., 2007; Kort \& Reilly, 2002). The learners were asked to evaluate the degree to which they felt a given course-related emotion (e.g., enjoyment of studying, boredom or sense of community) at a given time. In addition, the questionnaires included 13 statements that might explain learners' positive or negative experiences of the 
course, such as "others may find me incompetent". The emotional variables in the questionnaires were based on measures developed for assessing learners' emotions in technology-based learning environments (Hakkarainen et al., 2007) that have proven useful when measuring emotions related to learning (Kort \& Reilly, 2002). Furthermore, both questionnaires included five questions about the learners' backgrounds (gender, year of birth, field of study, years of study, prior experiences of simulation-based education) and one open-ended question that gave the learners space to write other comments. However, we did not get any responses to this. The questionnaires were delivered to the participants before and immediately after the simulation session, following the debriefing. In this study, we focused on the variables that measured learners' emotions and the statements that might explain them.

Data were analysed using descriptive statistics, factor analysis and Cronbach's alpha with the IBM SPSS Statistics 25 program. A paired-samples $t$ test with a Bonferroni correction was used to compare differences between the participants' emotions before and after the simulations (see also Keskitalo \& Ruokamo, 2017). In the factor analysis, the "fixed number of factors" command was used to determine how positive and negative emotions were distributed (e.g., Nummenmaa et al., 2013). The Cronbach's alphas were acceptable (Nunnally, 1978) for both of the subscales (0.84-0.89). Distribution was also supported by theoretical reasoning (e.g., Watson \& Tellegen, 1985). The negative emotions are shown in bold text and positive emotions in italic text in Table 2. A linear regression analysis was used to explain the variation in participants' emotions. For this purpose, the sum variables were aggregated from the variables that explained participants' positive or negative emotions. The sum variables were named "others' opinions", "goal-oriented studying", and "challenges set by the course". The Cronbach's alphas were also acceptable for these subscales (0.73-0.80) (Nunnally, 1978). In addition, the k-means cluster analysis was used to identify participants' emotional subgroups.

\section{Results}

\section{Descriptive statistics}

The descriptive statistics show that simulation-based learning aroused mainly positive emotions among the learners (see Table 1). In addition, positive emotions statistically significantly increased $(p<0.001)$ when positive emotions were compared before and after the simulations. Negative emotions statistically significantly decreased to a slight degree $(p<0.05)$ between the beginning and the end of the course.

Table 1

Mean and standard deviations of learners' positive and negative emotions before and after the course

\begin{tabular}{lllll}
\hline $\begin{array}{l}\text { Emotions before the } \\
\text { course (pre-questionnaire) }\end{array}$ & $M(S D)$ & $\begin{array}{l}\text { Emotions after the course } \\
\text { (post-questionnaire) }\end{array}$ & $M(S D)$ & Difference \\
\hline Positive emotions & $3.33(0.59)$ & Positive emotions & $3.68(0.65)$ & $0.35^{* * *}$ \\
Negative emotions & $2.07(0.64)$ & Negative emotions & $1.98(0.71)$ & $0.09^{*}$ \\
\hline
\end{tabular}

Note. ${ }^{*} p<0.05 ; * * p<0.01 ; * * * p<0.001$

In Table 2, we present the individual emotions' mean and standard deviations and their differences before and after the simulation-based course. 
Table 2

Mean and standard deviations of learners' emotions before and after the course

\begin{tabular}{|c|c|c|c|c|}
\hline $\begin{array}{l}\text { Emotions before the } \\
\text { course (pre- } \\
\text { questionnaire) }\end{array}$ & $M(S D)$ & $\begin{array}{l}\text { Emotions after the } \\
\text { course (post- } \\
\text { questionnaire) }\end{array}$ & $M(S D)$ & Difference \\
\hline Interest & $4.05(0.82)$ & Interest & $4.32(0.77)$ & $0.27 *$ \\
\hline Enjoyment of studying & $3.76(0.95)$ & Enjoyment of studying & $4.29(0.84)$ & $0.53 *$ \\
\hline Enthusiasm & $3.72(0.87)$ & Enthusiasm & $3.89(1.00)$ & 0.17 \\
\hline Hopefulness & $3.72(0.97)$ & Hopefulness & $3.89(1.11)$ & 0.17 \\
\hline Sense of community & $3.69(0.95)$ & Sense of community & $4.19(0.85)$ & $0.5^{*}$ \\
\hline Feelings of challenge & $3.55(1.06)$ & Feelings of challenge & $3.81(1.07)$ & 0.26 \\
\hline Cheerfulness & $3.33(0.91)$ & Cheerfulness & $3.55(1.04)$ & 0.22 \\
\hline Satisfaction & $3.24(1.01)$ & Satisfaction & $3.82(1.00)$ & $0.58 *$ \\
\hline Uncertainty & $3.21(1.13)$ & Uncertainty & $2.49(1.30)$ & $0.72 *$ \\
\hline Happiness & $3.12(0.98)$ & Happiness & $3.43(1.09)$ & $0.31 *$ \\
\hline Activity & $2.96(1.12)$ & Activity & $3.36(1.21)$ & $0.4^{*}$ \\
\hline Worry & $2.94(1.24)$ & Worry & $2.38(1.14)$ & $0.58 *$ \\
\hline Stress & $2.91(1.16)$ & Stress & $2.79(1.21)$ & 0.12 \\
\hline Tension & $2.78(1.27)$ & Tension & $2.62(1.26)$ & 0.16 \\
\hline Feelings of relief & $2.32(1.03)$ & Feelings of relief & $3.08(1.22)$ & $0.76^{*}$ \\
\hline Feelings of relaxation & $2.30(1.03)$ & Feelings of relaxation & $2.65(1.16)$ & $0.35^{*}$ \\
\hline Insufficiency & $2.21(1.13)$ & Insufficiency & $2.21(1.14)$ & 0.0 \\
\hline Frustration & $1.95(1.01)$ & Frustration & $2.10(1.12)$ & 0.15 \\
\hline Ingenuousness & $1.91(1.00)$ & Ingenuousness & $1.94(1.13)$ & 0.03 \\
\hline Jadedness & $1.88(1.08)$ & Jadedness & $1.70(0.97)$ & $0.18 *$ \\
\hline Feelings of deflation & $1.87(0.98)$ & Feelings of deflation & $1.98(1.07)$ & 0.11 \\
\hline Disappointment & $1.84(0.94)$ & Disappointment & $1.85(1.08)$ & 0.01 \\
\hline Irritability & $1.82(0.96)$ & Irritability & $1.73(1.01)$ & 0.09 \\
\hline Boredom & $1.80(0.98)$ & Boredom & $1.62(0.92)$ & 0.18 \\
\hline Feelings of shame & $1.63(0.86)$ & Feelings of shame & $1.83(1.10)$ & 0.2 \\
\hline Guilt & $1.61(0.93)$ & Guilt & $1.59(0.87)$ & 0.02 \\
\hline Irateness & $1.60(0.93)$ & Irateness & $1.47(0.80)$ & 0.13 \\
\hline Sadness & $1.59(0.77)$ & Sadness & $1.59(0.91)$ & 0.0 \\
\hline Ill humour & $1.56(0.88)$ & Ill humour & $1.57(0.96)$ & 0.01 \\
\hline
\end{tabular}

Note. $* p<0.05 ; * * p<0.01 ; * * * p<0.001$

bold text $=$ negative emotions; italic text $=$ positive emotions

The four most common positive emotions at the beginning of the course were interest $(M=4.05, S D=$ $0.82)$, enjoyment of studying $(M=3.76, S D=0.95)$, enthusiasm $(M=3.72, S D=0.87)$ and hopefulness $(M$ $=3.72, S D=0.97)$. Interest $(M=4.32, S D=0.77)$, enjoyment of studying $(M=4.29, S D=0.84)$ and sense of community $(M=4.19, S D=0.85)$ were also the most frequent positive feelings at the end of the course. Additionally, learners' interest $(p<0.05)$, enjoyment of studying $(p<0.05)$ and sense of community $(p<$ $0.05)$ were statistically significantly increased after the course, compared to pre-course emotions. Before the course, feelings of relief $(M=2.32, S D=1.03)$ and relaxation $(M=2.30, S D=1.03)$ were the least experienced positive feelings, but they were statistically significantly increased $(p<0.05)$ at the end of the course.

The most common negative emotions at the beginning of the course were uncertainty $(M=3.21, S D=$ $1.13)$, worry $(M=2.94, S D=1.24)$ and stress $(M=2.91, S D=1.16)$. Uncertainty $(M=2.49, S D=1.30)$ and worry $(M=2.38, S D=1.14)$ also had a statistically slightly significant decrease $(p<0.05)$ of all negative emotions after the course. Another statistically significant decrease in negative emotion was jadedness $(p<0.05)$. The negative feelings experienced least at the beginning of the course were ill humour $(M=1.56, S D=0.88)$, sadness $(M=1.59, S D=0.77)$ and irateness $(M=1.60, S D=0.93)$. Likewise, the least-experienced negative feelings at the end of the course were irateness $(M=1.47, S D=0.80)$, ill humour $(M=1.57, \mathrm{~S}=0.96)$, guilt $(M=1.59, S D=0.87)$ and sadness $(M=1.59, S D=0.91)$. 


\section{Multiple linear regression analysis as a means of explaining variations in participants' emotions}

Based on the multiple linear regression analysis, age $(t=2.068, p<0.05)$ and the way the participants were viewed by others (i.e., as a learner and as a physician; $t=8.415, p<0.001$ ) explained most variations in negative emotions before the simulations $\left(R^{2}=0.25\right)$, although the model's explanation level is not very high. The positive coefficient also indicates that higher age was associated more with the participants' negative emotions. Goal-oriented studying $(t=6.496, p<0.001)$ and challenges set by the course $(t=2.747$, $p<0.05)$ explained positive emotions before the course to some degree $\left(R^{2}=0.21\right)$. Only weak correlations were observed between individual variables and positive and negative emotions; thus, they are not reported here.

Based on the multiple linear regression analysis, age $(t=2.205, p<0.05)$ and others' views $(t=10.273, p$ $<0.001)$ also explained the greatest proportion of the variation in participants' negative emotions after simulation-based education $\left(R^{2}=0.32\right)$. According to the correlation analysis, the following individual variables correlated positively with negative emotions: "Others may find me incompetent" $(r=0.48, p<$ $0.01)$, "I cannot be sure that I have sufficient skills" $(r=0.43, p<0.01)$ and "I can lose the acceptance of others" ( $r=0.54, p<0.01)$. The challenges set by the course $(t=4.95, p<0.001)$ and goal-oriented studying $(t=6.777, p<0.001)$ explained the variation in participants' positive emotions after the simulations $\left(R^{2}=\right.$ 0.347). Based on the correlation analysis, the following three individual variables had the strongest positive correlation with positive emotions after simulation-based education: "I knew what to do to achieve the learning goals" ( $r=0.43, p<0.01)$, "The course objectives were clear to me" $(r=0.40, p<0.01)$ and "I set my own personal goals for the training' $(r=0.40, p<0.01)$.

\section{Participants' emotional profiles}

We used k-means cluster analyses to identify emotional subgroups within the participant groups. The participants were distributed into subgroups based on the previously developed sum variables (positive and negative emotions, others' opinions, goal-oriented studying and challenges set by the course). K-means cluster analyses by cases revealed three emotional subgroups before and after the simulation: engaged, anxious and neutral (see Table 3).

Table 3

Subgroup profiles before and after simulation-based education

\begin{tabular}{lccc}
\hline Before simulation & \multicolumn{3}{l}{} \\
\hline Variable & Engaged $(n=77)$ & Neutral $(n=69)$ & Anxious $(n=76)$ \\
\hline Positive emotions & 3.56 & 2.90 & 3.46 \\
Negative emotions & 1.59 & 2.23 & 2.40 \\
Others' opinions & 2.17 & 3.06 & 3.89 \\
Goal-orientedness & 3.81 & 3.17 & 3.75 \\
Challenges set by the course & 4.28 & 3.60 & 4.42 \\
\hline After simulation & & & \\
\hline Variable & Engaged $(n=73)$ & Neutral $(n=70)$ & Anxious $(n=86)$ \\
\hline Positive emotions & 4.22 & 3.29 & 3.56 \\
Negative emotions & 1.48 & 1.88 & 2.48 \\
Others' opinions & 1.88 & 2.30 & 3.67 \\
Goal-orientedness & 4.38 & 3.56 & 3.82 \\
Challenges set by the course & 4.48 & 3.55 & 4.24 \\
\hline
\end{tabular}

Engaged learners (before simulation, $n=77$; after simulation, $n=73$ ) had the highest scores on positive emotions $(M=3.56-4.22)$ and had low scores on negative emotions $(M=1.59-1.48)$. They were not as interested in others' opinions $(M=2.17-1.88)$ as the other two groups were. They also had high scores on goal-oriented studying $(M=3.81)$ and challenges set by the course $(M=4.28)$. Anxious learners (before simulation, $n=76$; after simulation, $n=86)$ had the highest scores on negative emotions $(M=2.40-2.48)$. They were highly concerned about others' opinions of themselves as learners and physicians $(M=3.89$ 3.67). They also scored highly on challenges set by the course $(M=4.42-4.24)$. Neutral learners (before simulation, $n=69$; after simulation, $n=70$ ) had a steady emotional profile; they received average scores on every variable. 


\section{Discussion}

The results confirm many previous studies that showed that simulation-based healthcare education is positively received (e.g., Schlairet et al., 2015). Similar to previous studies, this study revealed that simulation-based education produced positive emotions; however, this study also showed that these emotions increased towards the end of the course, thus surpassing learners' expectations (Keskitalo, 2012). The highest positive emotions before the simulation sessions were interest, enjoyment of studying, enthusiasm and hopefulness, which are also viewed as positive activating emotions (Lonka \& Ketonen, 2012; Peterson et al., 2015), although the aim was not to measure the arousal aspect of emotions (Reisenzein, 1994; Schnall, 2010). Although learning achievements were not measured in this study, due to possible mediating variables, we may assume that a positive learning experience facilitates learning; that is, it enhances cognitive flexibility, verbal fluency and decision-making ability, among other things (Dreisbach \& Goschke, 2004; Duffy et al., 2016). However, further study is needed to confirm this assumption.

Negative emotions, on the contrary, decreased to a slight degree during the courses. The most common negative emotions at the beginning of a simulation were uncertainty, worry and stress, which may, in small doses, enhance learning (DeMaria et al., 2010; Peterson et al., 2015). A valuable aspect of simulation-based learning is that learners' emotional responses are usually taken into account prior to the simulation by emphasising the confidentiality of the event and trying to set a safe scene for learning. The system also allows learners to make mistakes in a safe environment, and these mistakes are usually handled as teachable moments rather than as critiques of the learner. These emotional experiences are also discussed in a debriefing session after the simulation activity, as this offers a safe place to examine and learn to cope with difficult emotions (Andreatta et al., 2010; Keskitalo, 2015). This is something that higher education in general can adopt from simulation-based healthcare education, as learners may confront sensitive and stressful topics in fields other than medicine (cf. Leslie \& Hutchinson, 2018; see also Salmela-Aro \& Read, 2017).

In this study, we used multiple linear regression analysis to determine the reasons for participants' positive and negative emotions before and after the simulation sessions. We formed sum variables of the items that helped to explain learners' differing emotional experiences of the course, from positive to neutral to negative (Nummenmaa et al., 2013; Schnall, 2010). Emotional responses usually arise from the appraisal of the personal significance of an event (Lazarus, 1991), for example, the triggers of the learning environment. After the course, age and the thoughts of others explained most of the variation in learners' negative emotions, whereas challenges and goal-orientedness explained most of the learners' positive emotions. In other words, challenging participants and giving them activities that are at the appropriate level of difficulty can produce positive emotions (e.g., Duffy et al., 2016; Peterson et al., 2015). Reducing negative emotions and valuing and respecting the emotionally safe learning environment might be beneficial for participants who worry about their performance. Duffy et al. (2015) suggested using emotion regulation intervention, where facilitators specifically address emotions at the beginning of the sessions and the debrief to discuss any emotions that might affect the team's performance. Overall, medicine is an emotionally challenging field, where learners may also benefit from, for instance, the availability of support services or information on coping strategies (e.g., Leslie \& Hutchinson, 2018). According to our results, negative emotions tended to be higher among the older learners. Salmela-Aro and Read (2017) also found that burnout and inefficacy were more common among students who had been studying the longest. Thus, targeting counselling and support services for older learners who have been studying the longest is important (see also Salmela-Aro \& Read, 2017).

In this study, we identified three learners' emotional profiles: engaged, neutral and anxious. Although our study did not reveal how the different subgroups performed, the results were similar to those of Lonka and Ketonen (2012) and Peterson et al. (2015). We found that engaged learners had the most positive profile, and they were not very interested in others' opinions. They also had high scores on goal-oriented studying and challenge. We named the unstressed (cf. Lonka \& Ketonen, 2012) subgroup "neutral" because they had average scores on every variable. Anxious learners had the highest scores on negative emotions, and they were highly concerned about others' opinions of themselves as learners and physicians. They also scored highly on challenge. To target these emotional groups and guide the discussion with learners, facilitators could use, for example, validated questionnaires that are developed for diagnosing learners' exhaustion and engagement (e.g., Salmela-Aro \& Read, 2017). With these emotional profiles in mind, 
facilitators could tailor their teaching to motivate neutral learners or to build the confidence of anxious learners through positive but straightforward feedback, for instance. Anxious learners are most concerned about what other learners think of them; thus, building trust and a safe environment early on is especially important for them.

This study has some weaknesses. First, at the beginning of the study, the intent was to measure the participants' expectations and experiences of meaningful learning in SBLEs and not their emotions. Therefore, for future research, the questionnaires should be developed further to better consider basic academic emotions (e.g., Lonka \& Ketonen, 2012). However, we used the emotional variables that have previously been used successfully to measure participants' emotions (e.g., Hakkarainen et al., 2007; Kort $\&$ Reilly, 2002). Second, the study's questionnaires were used to measure the intensity of emotions through self-reports; participants reported their subjective feelings at a given time. In future studies, it would be good to use mixed methods to analyse quantitative and qualitative data to gain a deeper understanding of learners' emotions during simulation-based education (e.g., Duffy et al., 2015; Duffy et al., 2016). It would also be interesting to study emotional components (e.g., physiological, cognitive, motivational and expressive) other than subjective feelings through mixed methods, such as physiological measures or video recordings. Third, k-means cluster analysis is more dependent on the art of the researcher than science. The final cluster solution is often based on both objective and subjective interpretation (Hair et al., 1998); therefore, the emotional grouping needs further clarification. Fourth, during this study, we were not able to assess the participants' learning as we are educational scientists, not medical experts. This is certainly one of the deficiencies of this study. Therefore, future studies should also study how emotions are connected to academic success in simulation-based education (see Postareff et al., 2017) to provide further information on the connection between emotion and academic success within SBLEs.

\section{Conclusion}

In the words of Papert (n.d.), simulation-based learning can be described as "hard fun", as it produces positive experiences through challenges and goals. This may lead to enhanced learning and performance (DeMaria et al., 2010; McConnell \& Eva, 2012; Schwabe \& Wolf, 2009) and produce engagement and well-being in learners (Lonka \& Ketonen, 2012). This study complements our previous understanding of emotional experiences during simulation-based education (cf. Duffy et al., 2015) by revealing emotional subgroups of participants, which could help tailor instruction for individual learners. In addition, it reveals factors that may cause such emotional experiences, providing simulation facilitators areas to concentrate on in their instruction. Previous studies (e.g., Weller, 2004) have indicated that learners rate simulationbased education highly; however, some learners may benefit from individual guidance and support to reduce their anxiety and build their sense of medical competence (cf. Duffy et al., 2015; Postareff et al., 2017). Identifying struggling students requires simulation facilitators to be aware of emotions and their possible influences on learning, success and overall well-being. The knowledge gained from this study can be utilised to design increasingly successful educational settings for medical students that promote learning, emotional awareness and well-being, but they can also be used to improve higher education practices in general.

\section{Acknowledgements}

Tekes (the Finnish Funding Agency for Technology and Innovations), the European Regional Development Fund and a number of public and private financiers have provided the financing for this research as part of the Medi Peda III, MediPro and CRICS projects. The authors would like to thank the Center for Immersive and Simulation-based Learning group for their helpful comments and guidance and the teachers and students of Stanford University for their participation in this research. This study was also part of the research activities of the CICERO Learning Network, Finland (http://www.cicero.fi/).

\section{Declaration of interest}

The authors report no declaration of interest. 


\section{References}

Alinier, G., Hunt, W. B., \& Gordon, R. (2004). Determining the value of simulation in nurse education: Study design and initial results. Nurse Education in Practice, 4(3), 200-207. https://doi.org/10.1016/S1471-5953(03)00066-0

Alinier, G., Hunt, B., Gordon, R., \& Harwood, C. (2006). Effectiveness of intermediate-fidelity simulation training technology in undergraduate nursing education. Journal of Advanced Nursing, 54(3), 359-369. https://doi.org/10.1111/j.1365-2648.2006.03810.x

Andreatta, P. B., Hillard, M., \& Krain, L. P. (2010). The impact of stress factors in simulation-based laparoscopic training. Surgery, 147(5), 631-639. https://doi.org/10.1016/j.surg.2009.10.071

Bryson, E. O., \& Levine, A. I. (2008). The simulation theater: A theoretical discussion of concepts and constructs that enhance learning. Journal of Critical Care, 23(2), 185-187. https://doi.org/10.1016/j.jcrc.2007.12.003

Crossman, J. (2007). The role of relationships and emotions in student perceptions of learning and assessment. Higher Education Research \& Development, 26(3), 313-327. https://doi.org/10.1080/07294360701494328

Damasio, A. (2001). Descartesin virhe. Emootio, järki ja ihmisen aivot [Descartes' mistake: Emotions, intelligence and human brains]. Terra Cognita.

Damasio, A. R., Everitt, B. J., \& Bishop, D. (1996). The somatic marker hypothesis and the possible functions of the prefrontal cortex. Philosophical Transaction: Biological Sciences, 351(1346), 14131420. https://doi.org/10.1093/acprof:oso/9780198524410.003.0004

DeMaria, S., Bryson, E. O., Mooney, T. J., Silverstein, J. H., Reich, D. L., Bodian, C., \& Levine, A. I. (2010). Adding emotional stressors to training in simulated cardiopulmonary arrest enhances participant performance. Medical Education, 44(10), 1006-1015. https://doi.org/10.1111/j.13652923.2010.03775.x

Dieckmann, P. (2009). Simulation setting for learning in acute medical care. In P. Dieckmann (Ed.), Using simulations for education, training and research (pp. 40-138). Pabst Science Publishers.

Dieckmann, P., \& Rall, M. (2008). Designing a scenario as a simulated clinical experience: The TuPASS scenario script. In R. Kyle \& B. W. Murray (Eds.), Clinical simulation: Operations, engineering, and management (pp. 667-676). Academic Press.

Dreisbach, G., \& Goschke, T. (2004). How positive affect modulates cognitive control: Reduced perseveration at the cost of increased distractibility. Journal of Experimental Psychology: Learning, Memory, Cognition, 30(2), 343-353. https://doi.org/10.1037/0278-7393.30.2.343

Duffy, M. C., Azevedo, R., Sun, N.-Z., Griscom, S. E., Stead, V., Crelisten, L., Wiseman, J., Maniatis, T., \& Lachapelle, K. (2015). Team regulation in a simulated medical emergency: An in-depth analysis of cognitive, metacognitive, and affective processes. Instructional Science, 43, 401-426. https://doi.org/10.1007/s11251-014-9333-6

Duffy, M. C., Lajoie, S., \& Lachapelle, K. (2016). Measuring emotions in medical education: Methodological and technological advances within authentic medical learning environments. In S. Bridges, L. K. Chan, \& C. E. Hmelo-Silver (Eds.), Educational technologies in medical and health sciences: Advances in medical education (pp. 181-213). Springer.

Fraser, K., Irine, M., Teteris, E., Baxter, H., Wright, B., \& McLaughlin, K. (2012). Emotion, cognitive load and learning outcomes during simulation training. Medical Education, 46(11), 1055-1062. https://doi.org/10.1111/j.1365-2923.2012.04355.x

Fredrickson, B. (2001). The role of positive emotions in positive psychology: The broaden-and-build theory of positive emotions. American Psychologist, 56(3), 218-226. https://doi.org/10.1037/0003066X.56.3.218

Hair, J. F., Anderson, R. E., Tatham, R. L., \& Black, W. C. (1998). Multivariate data analysis (5th ed.). Prentice-Hall International, Inc.

Hakkarainen, P., Saarelainen, T., \& Ruokamo, H. (2007). Towards meaningful learning through digital video supported, case based teaching. Australasian Journal of Educational Technology, 23(1), 87109. https://doi.org/10.14742/ajet.1275

Helle, L., \& Säljö, R. (2012). Collaborating with digital tools and peers in medical education: Cases and simulations as interventions in learning. Instructional Science, 40, 737-744. https://doi.org/10.1007/s11251-012-9216-7

Hope, V., \& Henderson, M. (2014). Medical student depression, anxiety and distress outside North America: A systematic review. Medical Education, 48(10) 963-979. https://doi.org/10.1111/medu.12512 
Immordino-Yang, M. H. (2011). Implications of affective and social neuroscience for educational theory. Educational Philosophy and Theory, 43(1), 98-103. https://doi.org/10.1111/j.14695812.2010.00713.x

Immordino-Yang, M. H., \& Damasio, A. (2007). We feel, therefore we learn: The relevance of affective and social neuroscience to education. Mind, Brain and Education, 1(1), 3-10. https://doi.org/10.1111/j.1751-228X.2007.00004.X

Immordino-Yang, M. H., \& Faeth, M. (2010). The role of emotion and skilled intuition in learning. In D. Sousa (Ed.), Mind, brain and education: Neuroscience implications for the classroom (pp. 69-83). Solution Tree Press.

Jacques, A., Adkins, E., Knepel, S., Boulger, C., Miller, J., \& Bahner, D. (2011). Educating the delivery of bad news in medicine: Preceptorship versus simulation. International Journal of Critical Illness and Injury Science, 1(2), 121-124. https://doi.org/10.4103/2229-5151.84796

Keskitalo, T. (2012). Students' expectations of the learning process in virtual reality and simulation-based learning environments. Australasian Journal of Educational Technology, 28(5), 841-856. https://doi.org/10.14742/ajet.820

Keskitalo, T. (2015). Designing a pedagogical model simulation-based healthcare education (Publication No. 299) [Doctoral Dissertation, University of Lapland]. https://lauda.ulapland.fi/handle/10024/61885

Keskitalo, T., \& Ruokamo, H. (2017). Students' emotions in simulation-based medical education. Journal of Interactive Learning Research, 28(2), 149-159. https://www.learntechlib.org/primary/p/174188/

Kort, B., \& Reilly, R. (2002). Analytical models of emotions, learning, and relationships: Towards an affective-sensitive cognitive machine. In S. A. Cerri, G. Gouardères, \& F. Paraguaçu (Eds.), Proceedings of the 6th International Conference on Intelligent Tutoring Systems (pp. 955-962). Springer.

Lazarus, R. S. (1991). Emotion and adaptation. Oxford University Press.

Leslie, C., \& Hutchinson, A. D. (2018). Emotional distress when studying sensitive topics in psychology, and its relationship with hardiness and mental health. Higher Education Research \& Development, 37(3), 549-564. https://doi.org/10.1080/07294360.2018.1436525

Lonka, K., \& Ketonen, E. (2012). How to make a lecture course an engaging learning experience? Studies for the Learning Society, 2(3), 63-74. https://doi.org/10.2478/v10240-012-0006-1

Mauss, I. B., \& Robinson, M. D. (2009). Measures of emotions: A review. Cognition \& Emotion, 23(2), 209-237. https://doi.org/10.1080/02699930802204677

McConnell, M. M., \& Eva, K. W. (2012). The role of emotion in the learning and transfer of clinical skills and knowledge. Academic Medicine, 87(10), 1316-1322. https://doi.org/10.1097/ACM.0b013e3182675af2

Nummenmaa, L., Glerean, E., Hari, R., \& Hietanen, J. K. (2013). Bodily maps of emotions. Proceedings of the National Academy of Sciences of the United States of America, 111(2), 646-651. https://doi.org/10.1073/pnas.1321664111

Nunnally, J. C. (1978). Psychometric theory (2nd ed.). McGraw-Hill.

Papert, S. (n.d.). Hard fun. http://www.papert.org/articles/HardFun.html

Pekrun, R. (2006). The control-value theory of achievement emotions: Assumptions, corollaries, and implications for educational research and practice. Educational Psychology Review, 18(4), 315-341. https://doi.org/10.1007/s10648-006-9029-9

Pekrun, R., Elliot, A. J., \& Maier, M. A. (2006). Achievement goals and discrete achievement emotions: A theoretical model and prospective test. Journal of Educational Psychology, 98(3), 583-597. https://doi.org/10.1037/0022-0663.98.3.583

Pekrun, R., Goetz, T., Titz, W., \& Perry, R. P. (2002). Academic emotions in students' self-regulated learning and achievement: A program of qualitative and quantitative research. Educational Psychologist, 37(2), 91-105. https://doi.org/10.1207/S15326985EP3702 4

Peterson, E. R., Brown, G. T. L., \& Jun, M. C. (2015). Achievement emotions in higher education: A diary study exploring emotions across an assessment event. Contemporary Educational Psychology, 42, 82-96. https://doi.org/10.1016/j.cedpsych.2015.05.002

Pons, F., de Rosnay, M., \& Cuisinier, F. (2010). Cognition and emotion. In S. Järvelä (Ed.), Social and emotional aspect of learning (pp. 70-76). Elsevier.

Postareff, L., Mattsson, M., Lindblom-Ylänne, S., \& Hailikari, T. (2017). The complex relationship between emotions, approaches to learning, study success and study progress during the transition to university. Higher Education, 73(3), 441-457. https://doi.org/10.1007/s10734-016-0096-7

Reisenzein, R. (1994). Pleasure-arousal theory and the intensity of emotions. Journal of Personality and Social Psychology, 67(3), 525-539. https://doi.org/10.1037/0022-3514.67.3.525 
Rudolph, J. W., Simon, R., Raemer, D. B., \& Eppich W. J. (2008). Debriefing as formative assessment: Closing performance gaps in medical education. Academic Emergency Medicine, 15, 1010-1016. https://doi.org/10.1111/j.1553-2712.2008.00248.x

Salmela-Aro, K., \& Read, S. (2017). Study engagement and burnout profiles among Finnish higher education students. Burnout Research, 7, 21-28. https://doi.org/10.1016/j.burn.2017.11.001

Schlairet, M. C., Schlairet, T. S., Sauls, D. H., \& Bellflowers, L. (2015). Cognitive load, emotions, and performance in high-fidelity simulation among beginning nursing students: A pilot study. Journal of Nursing Education, 54(3), S5-S11. https://doi.org/10.3928/01484834-20150218-10

Schnall, S. (2010). Affect, mood and emotions. In S. Järvelä (Ed.), Social and emotional aspect of learning (pp. 59-64). Elsevier.

Schutz, P. A., \& DeCuir, J. T. (2002). Inquiry on emotions in education. Educational Psychologist, 37(2), 125-134. https://doi.org/10.1207/S15326985EP37027

Schutz, P. A., Quijada, P. D., de Vries, S., \& Lynde, M. (2010). Emotion in educational contexts. In S. Järvelä (Ed.), Social and emotional aspects of learning (pp. 64-69). Elsevier.

Schwabe, L., \& Wolf, O. T. (2009). Stress prompts habit behavior in humans. Journal of Neuroscience, 29(22), 7191-7198. https://doi.org/10.1523/JNEUROSCI.0979-09.2009

Staal, M. A. (2004). Stress, cognition, and human performance: A literature review and conceptual framework. NASA Ames Research Center.

Taylor, J. S. (2010). Learning with emotion: A powerful and effective pedagogical technique. Academic Medicine, 85(7), 1110. https://doi.org/10.1097/ACM.0b013e3181e202d3

Trigwell, K., Ellis, R. A., \& Han, F. (2012). Relations between students' approaches to learning, experienced emotions and outcomes of learning. Studies in Higher Education, 37(7), 811-824. https://doi.org/10.1080/03075079.2010.549220

Watson, D., \& Tellegen, A. (1985). Toward a consensual structure of mood. Psychological Bulletin, 98(2), 219-235. https://doi.org/10.1037/0033-2909.98.2.219

Weller, J. M. (2004). Simulation in undergraduate medical education: Bridging the gap between theory and practice. Medical Education, 38, 32-38. https://doi.org/10.1111/j.1365-2923.2004.01739.x

White, C. J. (2013). Higher education emotions: A scale development exercise. Higher Education Research \& Development, 32(2), 287-299. https://doi.org/10.1080/07294360.2012.674496

Corresponding author: Tuulikki Keskitalo, Tuulikki.Keskitalo@lapinamk.fi

Copyright: Articles published in the Australasian Journal of Educational Technology (AJET) are available under Creative Commons Attribution Non-Commercial No Derivatives Licence (CC BY-NC-ND 4.0). Authors retain copyright in their work and grant AJET right of first publication under CC BY-NC-ND 4.0 .

Please cite as: Keskitalo, T., \& Ruokamo, H. (2021). Exploring learners' emotions and emotional profiles in simulation-based medical education. Australasian Journal of Educational Technology, 37(1), 1526. https://doi.org/10.14742/ajet.5761 